\begin{tabular}{ll}
\hline \hline MINING AND METALLURGY INSTITUTE BOR & ISSN: 2334-8836 (Štampano izdanje) \\
UDK: 622 & ISSN: 2406-1395 (Online) \\
\hline \hline
\end{tabular}

UDK: $622.7: 519.816(045)=111$

doi:10.5937/mmeb1804027J

Ivana Jovanović, Nenad Magdalinović, Daniel Kržanović, Radmilo Rajković*

\title{
COMPARATIVE ANALYSIS OF AI MODELS IN THE MODELING OF FLOTATION PROCESS ${ }^{* *}$
}

\begin{abstract}
This paper presents a comparative overview the modeling results of flotation process from the Veliki Krivelj plant. Within the research, a total of ten models were formed using the various methods of soft computing - fuzzy logic, artificial neural networks and hybrid system ANFIS. It was found that the flotation concentration process is best modeled using artificial neural networks, where the best correlation coefficients between the actual and predicted values of copper content in concentrate and tailings, as well as the copper recovery in concentrate are achieved. They also gave the minimal RMSE in all cases.

Keywords: flotation, modeling, fuzzy logic, ANN, ANFIS
\end{abstract}

\section{INTRODUCTION}

Modern industrial flotation systems and demands for the high quality technological products require the accomplishment of complex tasks with a high precision, under the insufficiently defined conditions $[1,2]$. Classical process models and conventional control techniques do not provide enough effective results when it comes to such systems. On the contrary, there is an everyday need for inclusion the human factors (experts and/or operators) in the monitoring process, as well as the control and regulation of technological parameters. For these and similar reasons, a need arises to introduce the intelligent flotation control systems and soft computing based models, characterized by a certain degree of intuition in creating responses - analogous to human experts [3].

Intelligent control is a discipline where the control methods are developed so that they mimic important characteristics of hu- man intelligence - adaptation and lear-ning, planning under high uncertainty, and computing immense quantities of data $[4,5]$.

Motivation for the use of soft computing methods in modeling the flotation process is also the possibility of incorporating the expert heuristic knowledge into models, as well as increased flexibility in interpretation the obtained results .

For development of mathematical models, the flotation plant in Veliki Krivelj was chosen. This plant is an integral part of the Mining and Smelting Combine Bor [3].

\section{EXPERIMENTAL AND DEVELOPMENT OF MODELS}

For the purposes of this research, THE fuzzy logic, ANFIS and artificial neural network based flotation models have been developed. Their brief systematization is shown in Table 1.

\footnotetext{
* Mining and Metallurgy Institute Bor

** This investigation was conducted under the Project TR 33007 "Implementation of the Modern Technical, Technological and Ecological Design Solutions in the Existing Production Systems of the Copper Mine Bor and Copper Mine Majdanpek", funded by the Ministry of Education, Science and Technological Development of the Republic of Serbia
} 
Table 1 Basic data about models

\begin{tabular}{|c|c|c|c|c|c|c|c|c|c|}
\hline \multirow[b]{2}{*}{ SC Method } & \multirow[b]{2}{*}{ Label } & \multicolumn{5}{|c|}{ Input variables } & \multicolumn{3}{|c|}{ Output variables } \\
\hline & & $\begin{array}{l}\mathrm{Cu} \\
\text { content } \\
\text { in feed }\end{array}$ & $\begin{array}{l}\text { Collector } \\
\text { dosage } \\
\text { (roughing) }\end{array}$ & $\begin{array}{l}\text { Frother } \\
\text { dosage }\end{array}$ & $\begin{array}{c}\text { Pulp } \\
\mathrm{pH}\end{array}$ & $\begin{array}{c}\text { Collector } \\
\text { dosage } \\
\text { (scavenging) }\end{array}$ & $\begin{array}{c}\text { Final } \\
\text { concentrate } \\
\text { grade (CCU) }\end{array}$ & $\begin{array}{l}\text { Copper } \\
\text { recovery } \\
(\mathrm{RCU})\end{array}$ & $\begin{array}{c}\text { Final } \\
\text { tailings } \\
\text { grade } \\
\text { (TCU) } \\
\end{array}$ \\
\hline $\begin{array}{l}\text { Fuzzy logic } \\
\text { (Mamdani } \\
\text { system) }\end{array}$ & $\mathrm{EMM}^{*}$ & + & + & + & + & + & + & + & + \\
\hline $\begin{array}{l}\text { Fuzzy logic } \\
\text { (Takagi- } \\
\text { Sugeno } \\
\text { system) }\end{array}$ & ESM & + & + & + & + & + & + & + & + \\
\hline $\begin{array}{l}\text { Fuzzy logic } \\
\text { (Mamdani } \\
\text { system) }\end{array}$ & BMM & + & + & + & & & + & + & + \\
\hline $\begin{array}{l}\text { Fuzzy logic } \\
\text { (Takagi- } \\
\text { Sugeno } \\
\text { system) }\end{array}$ & BSM & + & + & + & & & + & + & + \\
\hline $\begin{array}{l}\text { Adaptive } \\
\text { neuro-fuzzy } \\
\text { system }\end{array}$ & ANF1 & + & + & + & & & + & & \\
\hline $\begin{array}{l}\text { Adaptive } \\
\text { neuro-fuzzy } \\
\text { system }\end{array}$ & ANF2 & + & + & + & & & & + & \\
\hline $\begin{array}{l}\text { Adaptive } \\
\text { neuro-fuzzy } \\
\text { system }\end{array}$ & ANF3 & + & + & + & & & & & + \\
\hline $\begin{array}{l}\text { Artificial } \\
\text { neural } \\
\text { networks }\end{array}$ & ANN1 & + & + & + & + & + & + & & \\
\hline $\begin{array}{l}\text { Artificial } \\
\text { neural } \\
\text { networks }\end{array}$ & ANN2 & + & + & + & + & + & & + & \\
\hline $\begin{array}{l}\text { Artificial } \\
\text { neural } \\
\text { networks }\end{array}$ & ANN3 & + & + & + & + & + & & & + \\
\hline
\end{tabular}

*BMM - Basic Mamdani Model, BSM - Basic Sugeno Model, EMM - Extended Mamdani Model,

ESM - Extended Sugeno Model

Data for models were collected from the industrial flotation plant "Veliki Krivelj". The ore processing in the plant includes: two-stage grinding and classification, rough flotation of copper minerals, regrinding of the rougher and scavenger concentrate, three-stage cleaning of copper concentrate and scavenging after the first cleaning.

Experimental research was performed in the virtual conditions, using the MATLAB programming language. The validation of the proposed flotation models was carried out in Microsoft Excel. More details on de velopment and results of these models are given in literature [3].

\section{COMPARATIVE ANALYSIS OF MODELS' OUTCOMES}

A comparative analysis of the modeling results was based on the correlation coefficient values and root mean square errors, obtained by the regression analysis. Figures 1 - 3 present the column chart diagrams showing the values of correlation coefficients, while Figures 4 - 6 present the column chart diagrams showing the root mean square errors for each of ten developed models. 


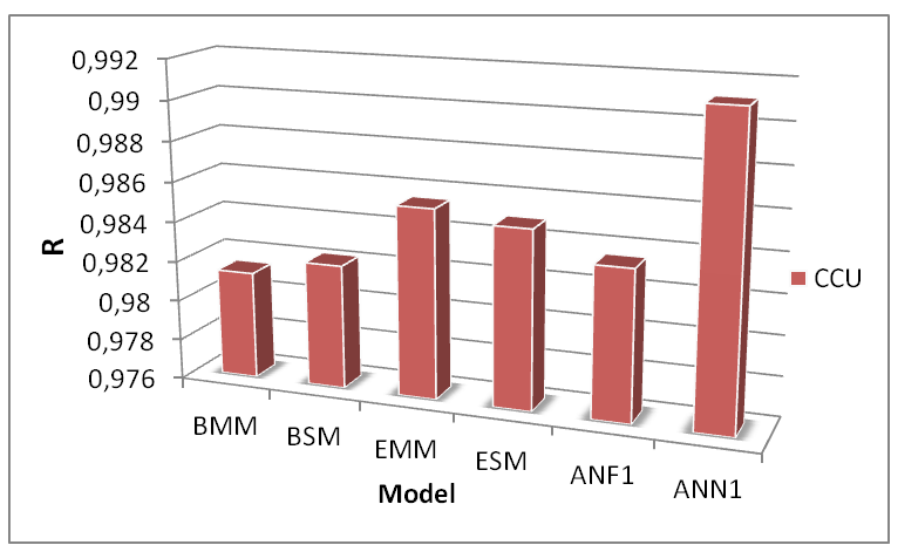

Figure 1 Correlation coefficients of the real and predicted values of copper content in the final concentrate.

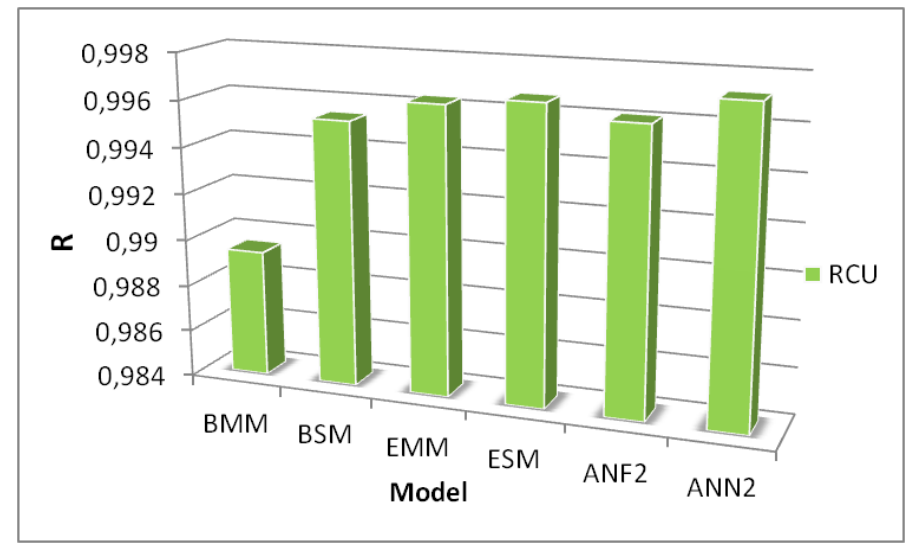

Figure 2 Correlation coefficients of the real and predicted values of copper recovery in the final concentrate.

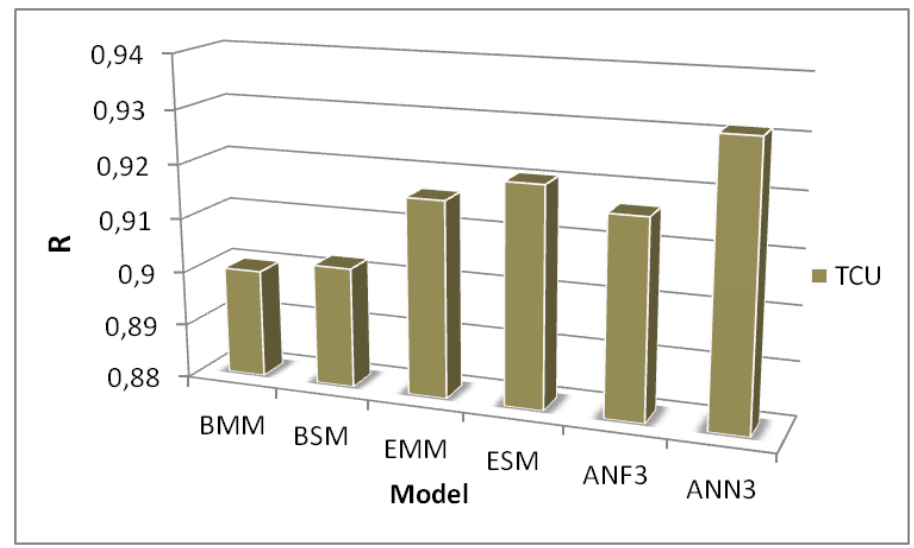

Figure 3 Correlation coefficients of the real and predicted values of copper content in the final tailings 


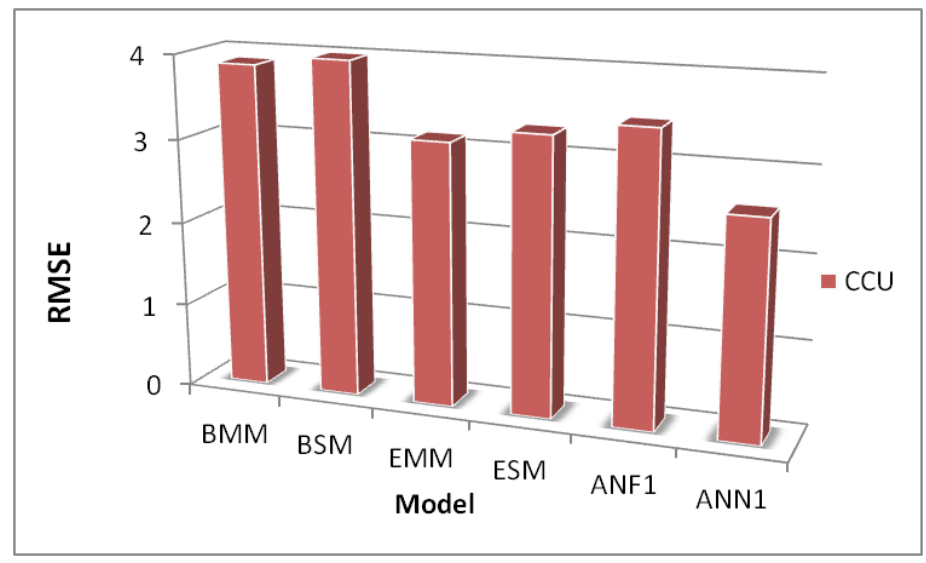

Figure 4 Root mean square errors of the copper content prediction in the final concentrate

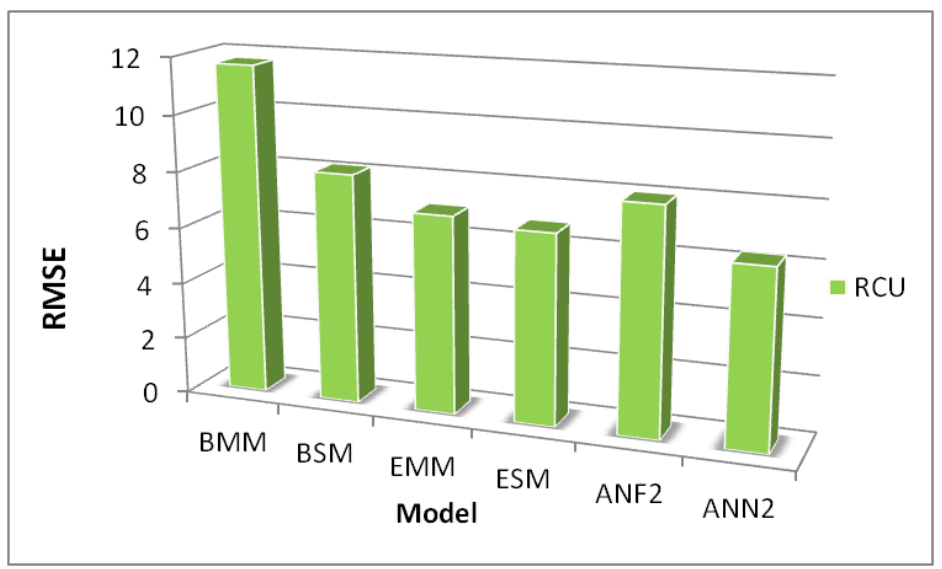

Figure 5 Root mean square errors of the copper recovery prediction in the final concentrate

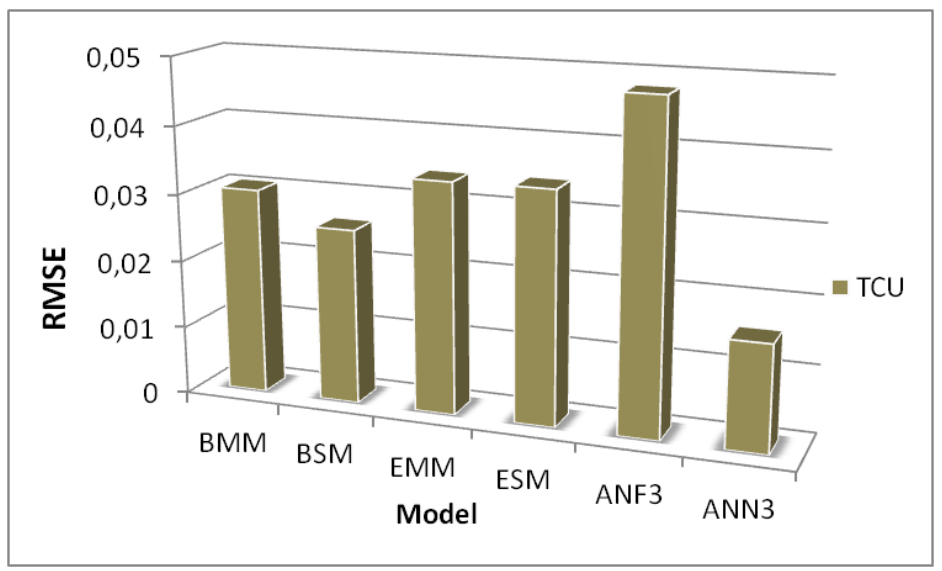

Figure 6 Root mean square errors of the copper content prediction in the final tailings 
Considering the results shown in Figures $1-3$, the obtained correlation coefficients are very high, which in general points to a good mutual relationship between the actual and predicted values of the output variables. However, the values of the root mean square error (Figures $4-6$ ) indicate a significant deviations between the values predicted by the models and real process data. The assumption is that these deviations occurred due to the fluctuations in the real process data that can be caused by the different factors, such as: variable process dynamics due to the stoppage in the plant operation, higher oscillations in the process parameters that were considered constant in models (grinding fineness, pulp density), imperfections of the reagent dosing devices, differences in the lime activity, quality of reverse water, etc.

The lowest correlation coefficients between the actual and predicted values were obtained in predicting the tailings grade, and this is generally valid for all models. The reason can lie in a relatively narrow range of real values of the tailings grade in relation to the concentrate grade and recovery (see Table 2). Therefore, the influences of completely different values of the input parameters can be integratedly manifested through very similar or same tailing grades, without considering this during modeling. This situation could significantly affect the correlation coefficients.

Table 2 Maximum and minimum measured values of the output parameters in the plant

\begin{tabular}{|c|c|c|c|}
\hline & CCU,\% & RCU,\% & TCU,\% \\
\hline Max & 28.09 & 96.48 & 0.15 \\
\hline Min & 7.91 & 40.78 & 0.01 \\
\hline
\end{tabular}

Also, any possible imperfections in the sampling of tailings (which are especially coupled with instabilities in the plant operation), should not be ignored, because it is an extremely small content of $\mathrm{Cu}$ in the samples, and therefore a proper sampling is crucial for obtaining the precise chemical composition of tailings.

The highest correlation coefficients between the actual and predicted values were obtained in predicting the copper recovery in the concentrate, which is also generally valid for all models. On the other hand, the highest RMSEs are present on diagrams related to the variable RCU. Such results indicate that in the process of achieving the balance of performances of the flotation plant "Veliki Krivelj", more complete performances are achieved regarding the concentrate grade. This conclusion does not mean that the copper recovery is ignored, but that the process is a "fine-tuned" in a direction of obtaining the highest concentrate grade. This would be the underlying reason for the maximum RMSE in modeling of the RCU variable, under thecircumstances in which it is confirmed that the soft computing models illustrate well the state and variations of the system. Also, this data shows how the additional information about the current state of the system can be obtained by the modeling of that system.

Although it has already been noted that all models have the high values of correlation coefficients, some differences can be established by the mutual comparison of modeling results. For example, the BMM model has some poorer correlation coefficients than the other models, and the RMSE indicate the significant deviations from the real values, especially when it comes to the variable CCU and RCU. Also, it can be claimed that the ANF3 model is the least adequate because, regardless of the high correlation coefficient, it has a large RMSE of predicting the copper content in tailings.

On the other hand, the artificial neural network models have shown the best predictive properties regarding to all three output flotation variables. Therefore, there is a hypothesis that the artificial neural networks better "overcome" the datasets in which a large scattering of values is present, or in the other words, provide the responses that better follow the fluctuations in the output datasets, at least in terms of flotation modeling. 
Generally speaking, performances of the fuzzy logic models with the five input variables (EMM, ESM) are somewhat better than the performances of fuzzy logic models with three input variables (BMM, BSM), especially regarding the copper concentrate grade and recovery. Based on this, it can be concluded that the introduction of a larger number of input variables leads to the improvement of predictive properties of this type of the flotation models. Therefore, there is a recommendation for development the fuzzy logic models with the six or more input variables. However, in this case, the maximum number of input parameters must be taken into account due to the size and complexity of the fuzzy logic rule base.

Finally, when it comes to comparing the fuzzy logic models with the models based on the hybrid ANFIS system, there are indications that the ANF1 model has better predictive properties than the BMM and BSM model in predicting the copper concentrate grade.

By mutual comparison the correlation properties of the BMM and BSM model, i.e. EMM and ESM model, and having in mind their root mean square errors of prediction, it was found that there is no significant difference of what fuzzy system is applied in the process of the flotation modeling (for the same conditions).

There are indications in literature that the Takagi-Sugeno method gives some better results regarding to modeling the same processes, under the identical conditions [3]. Accordingly, in this particular case, there are certain differences in favor of the TakagiSugeno method, but these differences are not distinctive.

\section{CONCLUSION}

Within this research, a total of ten flotation models were developed using the various soft computing methods - fuzzy logic, hybrid system ANFIS and artificial neural networks. Their predictive properties were compared by means of correlation coefficients $(\mathrm{R})$ and root mean square prediction errors (RMSE). In general, it has been ob served that all methods give the high correlation coefficients between the actual and predicted values of output parameters, but some differences can be noticed among them. The highest values of Rare given by the artificial neural networks, while the lowest $\mathrm{R}$ values are given by the fuzzy logic models with the three input variables. Concerning the RMSE, this value is the lowest for the ANN models, and the highest for fuzzy logic models with the three input variables (copper content and recovery in the final concentrate) and ANFIS (copper content in the final tailings). Therefore, it can be concluded that the artificial neural networks present the most suitable tool for flotation modeling, when it comes to the soft computing methods.

\section{REFERENCES}

[1] Chanturia V.A., Innovations in a Comprehensive and Profound Mineral Processing in Russia, Rudarski glasnik (Bulletin of Mines), No 1-2, pp. 5 - 30, 2016.

[2] Radosavljević M., Vujić S., Filipović J., Boševski T., Praštalo Ž., Functional Correlativity of an Integrated Management System and Mining Processes, Rudarski glasnik (Bulletin of Mines), No 1-2, pp. 43 - 51, 2016

[3] Jovanović I. Model of an Intelligent Adaptive Management System of the Ore Processi)ng Process, Faculty of Mining and Geology, Belgrade, $\mathrm{PhD}$ thesis, p. 217, 2016. (in Serbian)

[4] Jovanović I., Magdalinović S., Mikić M., Miljanović I., Possibilities of Introducing an Intelligent Control System in the Flotation Plant Veliki Krivelj, Mining and Metallurgy Engineering Bor 3-4/2017, pp. 85 - 90, 2017.

[5] Jovanović I., Nešković J., Petrović S., Milanović D., A Hybrid Approach to Modeling the Flotation Process from the "Veliki Krivelj" Plant, Mining and Metallurgy Engineering Bor 1-2/2018, pp. $1-10,2018$. 